\title{
A Leadership Development Program for Radiology Residents
}

\author{
Darel E. Heitkamp MD ${ }^{a}$ \\ William D. Kerridge MD ${ }^{b}$ \\ Zachary E. Ballenger MD ${ }^{c}$ \\ Alexander M. Tawadros MD ${ }^{\mathrm{d}}$ \\ Richard B. Gunderman MD, PhD, $\mathrm{MPH}^{\mathrm{e}}$ \\ ${ }^{a}$ Department of Radiology and Imaging Sciences, Indiana University School of Medicine, Indiana \\ University Hospital, Indianapolis, Indiana \\ ${ }^{\mathrm{b}}$ Department of Radiology \& Biomedical Imaging, University of California, San Francisco, San \\ Francisco, California \\ ${ }^{\mathrm{c}}$ Lubbock Diagnostic Radiology, Lubbock, Texas \\ ${ }^{\mathrm{d}}$ Radiology, Inc, Mishawaka, Indiana \\ e Department of Radiology and Imaging Sciences, Indiana University School of Medicine, Indianapolis, \\ Indiana
}

\section{The Problem: Too Few Leadership Curricula for Radiology Residents}

Radiologists today require a diverse skill set to navigate the challenges of transitioning to a value-based model of care delivery. Indeed, competence in many noninterpretive domains is necessary to more effectively add value to patient care and radiology practice groups [1-10]. These related content areas include professionalism, ethics, health care economics, clinical practice management, informatics, quality, evidence-based medicine, patient- and family-centered care, and cultural competency, to name just a few.

This is the author's manuscript of the article published in final edited form as:

Heitkamp, D. E., Kerridge, W. D., Ballenger, Z. E., Tawadros, A. M., \& Gunderman, R. B. (2017). A Leadership Development Program for Radiology Residents. Journal of the American College of Radiology, 14(11), 1468-1470. https://doi.org/10.1016/j.jacr.2017.05.005 
The importance of these new content domains has been recognized in the radiology literature and at national radiology conferences. Novel programs designed to teach these leadership skills to radiology residents have been developed at several institutions, focusing on areas such as the business of health care [11-13], radiologists as consultants [14], health care policy [15,16], and clinical practice management $[17,18]$. Yet despite the widespread acknowledgment that these kinds of leadership skills are vital to the development of tomorrow’s radiologists, few residency training programs have established dedicated curricula focusing on comprehensive leadership education [19-21].

\section{What Was Done: A Resident Development Program in Leadership}

In July 2008, resident and faculty organizers at the Indiana University Department of Radiology established the Resident Leadership Group (RLG), a voluntary department-sponsored organization designed to expose trainees to the building blocks of leadership. The stated goals of the group were 2fold: (1) to enable the development of leadership skills essential for success in radiology today, such as communication, mentorship, professionalism, health care economics, health services research, quality, and clinical practice management, and (2) to provide a positive forum for open discourse, where radiologists feel comfortable sharing opinions, discussing problems and ideas, and learning from the diverse experiences of the group.

\section{Structure and Support}

Group membership has grown from 12 resident members in 2008 to more than 40 resident members in 2017 and has always included at least two faculty moderators. Meetings are held regularly every 2 weeks over the noon hour, with lunch provided. Agendas are generally determined by group consensus with guidance from faculty moderators. Meeting topics vary but often include resident-led discussion of articles relating to health care economics, health policy, and practice management.

The group has strong support from the residency director and department chairman and is recognized by the department with an annual operating budget of $\$ 5,000$. This is used primarily to provide lunch and to 
purchase group reading materials. Participation in the RLG is strictly voluntary, and residents are allowed to join or leave at any time. First-year residents are encouraged to join at the very outset of residency.

\section{Curriculum}

\section{Discussion of the Literature}

The RLG critically reviews articles from many journals regarding a diverse range of topics, including qualities of effective leadership, the business of radiology, health care economics, organizational leadership, and health policy. The Harvard Business Review and JACR are two journals from which many of the group's readings have been obtained to date. Before each meeting, specific teams of residents are assigned duties as either discussion leaders or scribes so that group discussion stays on task, and careful notes of every meeting are recorded. In our experience, valuable lessons in organization and communication are learned by the residents assigned to lead group discussion.

\section{Manuscript Development}

Group discussion often yields novel ideas relating to leadership and education. In many cases, the recorded notes serve as excellent outlines for potential manuscripts. The resident discussion leaders and note takers for each meeting are encouraged to participate in the manuscript writing and editing process for their topic. To date, 27 articles have been written and published in our core radiology journals— JACR, Radiology, Academic Radiology, and the American Journal of Roentgenology—all stemming from novel ideas generated during interactive group discussion of the RLG.

\section{Book Series}

The RLG also explores leadership skills through a diverse ongoing book series. Titles on the group’s reading list are often not directly related to medicine but instead examine leadership from the perspective of other industries. Some books chosen by the group have explored the psychology of success, such as Emotional Intelligence by Daniel Goleman. Others examine successful traits of visionary companies and 
individuals, such as Built to Last by Jim Collins, The Seven Habits of Highly Effective People by Stephen Covey, and It's Your Ship by D. Michael Abrashoff.

\section{Local and National Leadership Opportunities}

The group works hard to match the interests of its resident members to leadership opportunities on both local and national fronts. This includes pursuing service opportunities within the department and medical school, developing and expanding the resident and fellow section of our state radiology society, seeking out leadership opportunities within national radiology societies such as the Association of University Radiologists (AUR) and the ACR, and participating in organized academic development programs such as the RSNA/AUR/ARRS Introduction to Academic Radiology Program and the AUR Radiology Resident Academic Leadership Development Program. Residents are also encouraged to pursue other available opportunities, such as the annual leadership summit of the Radiology Leadership Institute and the many scholarships and fellowships offered by the ACR.

\section{Resident Leadership Projects}

Resident members are encouraged to design and conduct their own research projects with the help of department faculty mentors. Many diverse prospective and retrospective projects have been performed over the years that highlight various aspects of health care economics, radiology workflow, and practice management. Some residents have designed important projects that also serve to fulfill their ACGME requirement for participation in a systems-based practice exercise. These learning activities are shared closely with the RLG and the entire radiology department and then written up for presentation at national meetings and/or submission to radiology journals.

\section{Outcomes}

A seven-question web-based survey (SurveyMonkey, Palo Alto, California) was distributed by e-mail to the 98 participants of the RLG who have subsequently graduated from our residency and entered radiology practice. The survey was sent after the eighth full year of group operation. Survey questions 
were designed to elicit opinions of how well the RLG prepares trainees for careers in radiology practice and how quickly after leaving residency former RLG members were able to assume leadership positions within their groups. Twenty-five members responded, for a response rate of $26 \%$. This response rate compares favorably with the industry average of $10 \%$ to $15 \%$ for external surveys of nonemployees.

The results of the survey revealed that most responding participants (92\%) felt better prepared for their careers as practicing radiologists having been in the group. A substantial percentage of participants (35\%) had assumed leadership roles in their radiology groups or hospital systems within 3 years of entering practice. Freeform comments revealed that specific areas in which participants felt that the RLG helped them in their practice included communication, interacting with referring physicians, career development, understanding the business of radiology, team building, group dynamics, and interacting with hospital administration.

Many outstanding resident leadership projects have been completed and showcased in both the radiology literature and at national radiology meetings. Examples of projects include a comprehensive survey of all radiology groups in the state of Indiana that highlighted group composition and hiring trends, group relationships to hospitals and imaging centers, and direction of practice; a quality analysis at our local Veterans Affairs hospital focusing on report turnaround time, measuring each step of the process from the clinician's order to the radiologist's signing of the final report; and the creation of a new educational collaboration that resulted in a semester-long MBA course in health care economics for our radiology residents taught by campus business school faculty members [22].

Resident members have strategically sought out additional learning opportunities and leadership roles on both the local and national levels. Some have won scholarships to attend the Radiology Leadership Institute’s annual leadership summit, whereas others have sought leadership positions and worked to expand our state ACR chapter's resident and fellow section. Our chief residents have been active in leadership roles within the American Alliance of Academic Chief Residents in Radiology. We have also 
led an aggressive campaign to send many residents to the ACR AMCLC so they may be active participants in radiology advocacy.

\section{Conclusions}

The RLG at Indiana University is a successful multifaceted development program that exposes trainees to many of the complex noninterpretive issues facing health care leaders today. The group focuses on providing a forum for engaging discussion and critical thinking and on allowing a strategic approach to pursuing leadership opportunities both locally and nationally. Comments from alumni of this program reflect the vital role the group provides in developing tomorrow's radiology leaders. We believe the model could be reproduced to create similar leadership development programs at other institutions. 


\section{References}

1 P.J. Slanetz, M.E. MullinsRadiology education in the era of population-based medicine in the United States Acad Radiol, 23 (2016), pp. 894-897

2 Z. Cizman, M. Hammer, B. Mollard, et al. A resident perspective on adding value as radiologists Acad Radiol, 23 (2016), pp. 517-520

3 R.A. Mackey, Z. Ballenger Lessons learned at the Radiology Leadership Institute - Kellogg Leadership Development Program: a resident’s perspective J Am Coll Radiol, 11 (2014), pp. 433-434

4 L. DeitteThe new residency curriculum: professionalism, patient safety, and more J Am Coll Radiol, 10 (2013), pp. 613-617

5 T.J. Amrhein, A. Tabesh, H.R. Collins, L.L. Gordon, J.A. Helpern, J.H. JensenInstituting a radiology residency scholarly activity program Educ Health (Abingdon), 28 (2015), pp. 68-73

6 P. Cronin, J.V. Rawson, M.E. Heilbrun, et al. How to critically appraise the literature Acad Radiol, 21 (2014), pp. 1117-1128

7 J. Chertoff, E. Pisano, B. GertCore curriculum: research ethics for radiology residents Acad Radiol, 16 (2009), pp. 108-116

8 B.A. Lown, J.P. Sasson, P. Hinrichs Patients as partners in radiology education: an innovative approach to teaching and assessing patient-centered communication Acad Radiol, 15 (2008), pp. 425-432

9 H.J. Otero, B.N. Weissman, F.J. Rybicki System-based practice: proposal for a comprehensive curriculum Acad Rdiol, 15 (2008), pp. 119-126 
10 K.M. Siddiqui, D.L. Weiss, A.P. Dunne, B.F. Branstetter Integrating imaging informatics into the radiology residency curriculum: rationale and example curriculum J Am Coll Radiol, 3 (2006), pp. $52-57$

11 T.A. McArthur, E.L. Prince, L.L. Berland, et al. Introduction to business for radiology senior residents J Am Coll Radiol, 8 (2011), pp. 205-208

12 A.S. Prober, W.A. Mehan, H.S. Bedi Teaching the healthcare economics milestones to radiology residents: our pilot curriculum experience Acad Radiol, 23 (2016), pp. 885-888

13 A.S. Prober, E. Ledermann, A. Norbash, W.A. Mehan, H.S. Bedi Fulfilling the health care economics milestones: adopting an online curriculum for radiology residency programs J Am Coll Radiol, 12 (2015), pp. 314-317

14 M.D. Mamlouk, A. Anavim, S.C. Goodwin Radiology residents rounding with the clinical teams: a pilot study to improve the radiologist's visibility as a consultant J Am Coll Radiol, 11 (2014), pp. 326-328

15 J.R. Medverd, D.L. Dicks, J. Tang, et al. Business of radiology 101: the state of radiology business practice and health care policy curricula at US radiology residency programs J Am Coll Radiol, 9 (2012), pp. 174-180

16 I.M. DeQuesada, F.H. Chokshi, M.E. Mullins, R. Duszak Practice management and health policy education in radiology: an emerging imperative J Am Coll Radiol, 12 (2015), pp. 1085-1092 17 S. Chan Management education during radiology residency: development of an educational practice Acad Radiol, 11 (2004), pp. 1308-1317

18 C.J. Brandon, P.B. Mullan Teaching medical management and operations engineering for systems-based practice to radiology residents Acad Radiol, 20 (2013), pp. 345-350 
19 E.F. Donnelly A leadership development curriculum for radiology residency J Grad Med Educ, 7 (2015), pp. 296-297

20 Donnelly EF. Developing leaders, not just readers: implementing a leadership curriculum. Presented at: 2013 Annual Meeting of the Association of University Radiologists. Available at: http://apdr.org/WorkArea/DownloadAsset.aspx?id=1089. Accessed February 11, 2017.

21 Heitkamp DE. Mentoring leadership in radiology residency training. Presented at: 2009 Annual Meeting of the Association of University Radiologists. Available at: http://apdr.org/WorkArea/DownloadAsset.aspx?id=464. Accessed February 11, 2017.

22 R.B. Gunderman, A.M. Tawadros. Business education for radiology residents: the value of fulltime business educators. Acad Radiol, 18 (2011), pp. 645-649 